Am. J. Trop. Med. Hy.g. 51(5), 1994, pp. 648-658

Copyright (1) 1994 by The American Society of Tropical Medicine and Hygiene

\title{
A STRONG ASSOCIATION BETWEEN MEFLOQUINE AND HALOFANTRINE RESISTANCE AND AMPLIFICATION, OVEREXPRESSION, AND MUTATION IN THE P-GLYCOPROTEIN GENE HOMOLOG (pfmdr) OF PLASMODIUM FALCIPARUM
} IN VITRO

\author{
SHEILA A. PEEL, PATRICIA BRIGHT, BOYD YOUNT, \\ JEAN HANDY, AND RALPH S. BARIC \\ Department of Epidemiology, School of Public Health, University of North Carolina at Chapel \\ Hill, Chapel Hill, North Carolina; Department of Microbiology and Immunology, School of \\ Medicine, University of North Carolina at Chapel Hill, Chapel Hill, North Carolina
}

\begin{abstract}
Stepwise selection for increased mefloquine resistance in a line of Plasmodium falciparum in vitro resulted in increased resistance to halofantrine and quinine, increased sensitivity to chloroquine, and amplification and overexpression of the P-glycoprotein gene homolog ( $p f m d r l)$. A point mutation (tyrosine to phenylalanine) noted at amino acid 86 in pfmdrl in the mefloquine-resistant line W2mef was amplified in more resistant lines derived from it by in vitro selection pressure with mefloquine. Conversely, lines selected for increased chloroquine resistance exhibited a revertant phenotype that was sensitive to mefloquine and halofantrine. These lines also demonstrated increased sensitivity to quinine, loss of amplification of pfmdrl, loss of the mefloquine/halofantrine phenylalanine- 86 mutation, and selection for a tyrosine-86 mutation previously associated with chloroquine resistance. These findings provide strong evidence for $p$ fmdrl mediating crossresistance to halofantrine and mefloquine in $P$. falciparum in vitro.
\end{abstract}

Plasmodium falciparum, the most lethal human malaria parasite, has become increasingly difficult to control since strains have emerged that are resistant not only to established antimalarials such as chloroquine and quinine, but also to newer therapeutic agents such as mefloquine, halofantrine, and artemisinin. ${ }^{1.2}$ Although the mechanism(s) of resistance to these drugs has not been elucidated, resistance may be similar to the multidrug-resistant (MDR) phenotype observed in mammalian tumor cell lines, which is characterized by decreased intracellular drug accumulation, increased cellular drug efflux, and cross-resistance to a variety of structurally diverse lipophilic cyclic compounds. ${ }^{3}$ In MDR tumor cells, this phenotype is mediated by the enhanced expression of a 120-180 kD plasma membrane glycoprotein, termed P-glycoprotein, which functions as a putative ATP-dependent efflux pump. ${ }^{3}$ Drug efflux is inhibited by calcium antagonists, tricyclic antidepressants, and antihistaminics. ${ }^{4}$

Although the classic MDR phenotype has not been demonstrated in $P$. falciparum, resistance derived to one quinoline-containing antimalarial in vitro resulted in altered susceptibilities to oth- er quinoline-containing compounds. ${ }^{5.6}$ Sensitive and resistant parasites accumulate chloroquine at similar rates while chloroquine-resistant parasites eliminate drug 40-50 times more rapidly. ${ }^{7}$ It is not known whether mefloquine is rapidly eliminated from the parasite since efflux studies with this extremely lipophilic drug have not yet been successful. Agents that reverse the MDRresistant phenotype have also been successfully used to inhibit drug efflux from chloroquine-resistant parasites, but not from chloroquine-sensitive ones. ${ }^{8-10}$ Penfluridol, a neuroleptic drug, reversed mefloquine and halofantrine resistance in $P$. falciparum in vitro ${ }^{11.12}$ and mefloquine resistance in $P$. yoelii in vivo. ${ }^{13}$ No compound, however, has been identified that modulates resistance to all the quinoline-containing antimalarials; thus, the mechanisms may be independent.

Two MDR-like P-glycoprotein gene homologs, pfmdrl and pfmdr2, have been identified in $P$. falciparum, ${ }^{14,15}$ and they share predicted structural motifs associated with the superfamily of ATP-binding cassette (ABC) transporter proteins. ${ }^{16}$ Gene amplification and overexpression of pfmdrl have been demonstrated in some chlo- 
roquine-resistant isolates, ${ }^{14.17}$ in a mefloquine-resistant line in vitro, ${ }^{15}$ and in MDR isolates from Thailand; ${ }^{17}$ however, direct linkage of $p$ fmdrl to resistance to these antimalarials has not been proven. Point mutations in pfmdrl have also been associated with chloroquine and mefloquine resistance, ${ }^{17 .} 18$ but it has not been determined whether these mediate resistance since results from different laboratories have been contradictory. Neither chloroquine nor mefloquine resistance was linked to the pfmdrl gene following restriction fragment length polymorphism analysis of a laboratory cross of chloroquine-sensitive and -resistant parasites; ${ }^{19.20}$ rather, chloroquine resistance was mapped to a locus on chromosome 7 that was independent of the pfmdrl allele. ${ }^{20}$ In support of these findings, selection for increased chloroquine resistance in an MDR parasite containing three copies of the pfmdrl allele resulted in loss of amplification of this allele. Increased sensitivity to mefloquine was also noted, suggesting a relationship of pfmdrl with mefloquine resistance. ${ }^{21}$ In this paper, we have examined the role of pfmdrl in the acquisition of mefloquine resistance in a series of highly resistant/sensitive parasite lines.

\section{MATERIALS AND METHODS}

Parasite lines. The parasites W2 and W2mef were derived in our laboratory from the Indochina III strain, ${ }^{5}$ and strain FCR3-Gambia was obtained from Dr. William Trager (Rockefeller University, New York, NY). The lines Mef 55, Mef 100, Mef 300, and Mef 2.4 were derived from $\mathrm{W} 2 \mathrm{mef}$ by high-dose relapse drug pressure and were grown using standard methods of in vitro cultivation as previously described. ${ }^{6}$ Selection protocols for derivation of increased chloroquine resistance from $\mathrm{W} 2 \mathrm{mef}$ were as previously described. ${ }^{6}$

Drug susceptibility profiles. The index of antimalarial activity was assessed using ${ }^{3} \mathrm{H}$-hypoxanthine incorporation microdilution assays as previously described.6.22 The 50\% inhibitory concentrations $\left(\mathrm{IC}_{50}\right)$ of chloroquine diphosphate (Sigma, St. Louis, MO), mefloquine hydrochloride (Walter Reed Army Institute Research [WRAIR], Washington, DC), quinine sulfate (Sigma), halofantrine hydrochloride (WRAIR), and artemisinin (WRAIR) were determined by nonlinear regression analysis of dose-response data for 5-11 independent assays. ${ }^{22}$ All inhibi- tory concentration measurements were statistically analyzed and are presented as the mean \pm standard deviation. Statistical significance of measurements was determined by a one-way analysis of variance with a post hoc contrast to compare group means.

Nucleic acid extraction. Parasites were isolated from asynchronous cultures by saponin lysis, and genomic DNA was extracted essentially as described. ${ }^{23}$ Stage-specific parasites were enriched by sedimentation through Percoll gradients, ${ }^{24}$ and total RNA was extracted by acid guanidinium thiocyanate phenol-chloroform methods. ${ }^{25}$

DNA probes. Gene probes were generated by polymerase chain reaction (PCR) methodology using the following deoxyoligonucleotide primers derived from known plasmodial sequences: 1) CCAGGAATACCAGTGC and CTTTACCTTCACGACC for PCR of the circumsporozoite protein $(C S P) ;^{26} \quad$ 2) GGAGGATTATATCCCG and CAGCTGCAACAATTGG for pfmdrl; and 3) GCTGAAGGAGAAGATACG and GGTTTTCCAGATTCTTC for the glycophorin binding protein $(G B P)$ gene. ${ }^{27}$ Radiolabeled probes specific for either the $C S P, G B P$, or pfmdrl genes were obtained using Qiagen gel extraction protocols (Qiagen Inc., Chatsworth, CA). The DNA was extracted with phenol:chloroform:isoamyl alcohol, precipitated, and radiolabeled using the Random Primers DNA Labeling System (GibcoBRL, Gaithersburg, MD). Free nucleotides were removed by spin-column chromatography. ${ }^{28}$

Analysis of gene copy number. Genomic DNA was restricted with the appropriate restriction endonuclease, electrophoresed on $0.7 \%$ agarose gels, then transferred to nitrocellulose (Schleicher and Schuell, Keene, NH). ${ }^{29}$ Blots were hybridized at $42^{\circ} \mathrm{C}$ with $2 \times 10^{6} \mathrm{cpm} / \mathrm{ml}$ of probe in $50 \%$ formamide (Sigma), $5 \times$ SSPE (0.9 M NaCl, $50 \mathrm{mM}$ sodium phosphate, $\mathrm{pH}$ 7.7, $5 \mathrm{mM}$ EDTA), $5 \times$ Denhardt's solution $(0.1 \%$ Ficoll, $0.1 \%$ bovine serum albumin, $0.1 \%$ polyvinylpyrolidone), $100 \mu \mathrm{g} / \mathrm{ml}$ of polyadenylic acid (Sigma), and $0.2 \%$ Tween 20 (Sigma). The nonspecific background was removed by washing the blots with $0.1 \times$ SSPE, and $0.1 \%$ sodium dodecyl sulfate at $65^{\circ} \mathrm{C}$. Filters were exposed to XAR film (Eastman Kodak, Rochester, NY) at $-70^{\circ} \mathrm{C}$. Gene copy number was computed using AMBIS ${ }^{\top}$, a radioanalytical imaging system (AMBIS Systems, Inc., San Diego, CA). Blots were counted over a 12-24-hr period, windows 
for pfmdrl were counted, and background signal was subtracted. Blots were then stripped of probe by immersion in $10 \mathrm{mM}$ Tris, $\mathrm{pH} 8.0,1$ mM EDTA, $0.1 \times$ Denhardt's solution for $2 \mathrm{hr}$ at $75^{\circ} \mathrm{C}$, rinsed with $0.1 \times$ SSPE at room temperature, drained, and then exposed to XAR film to ensure removal of probe. The blots were reprobed with the CSP gene probe, scanned with AMBIS, and the ratios of signal for pfmdrl to CSP were calculated for each line and normalized to the ratios obtained for W2, which demonstrates a single copy of pfmdrl.

DNA cloning and sequencing. The PCR amplified gene fragments of pfmdrl ( $5^{\prime}$ primer: $497-514 ; 3^{\prime}$ primer: $1002-983$; 5' primer: 497514; 3' primer: 1138-1121) were ligated into either PCR 1000 (Invitrogen, San Diego, CA) or pGEM-T (Promega, Madison, WI) using the TA cloning systems (Invitrogen and Promega), ${ }^{14}$ transformed into INVaF' (PCR 1000) (Invitrogen) or DH5- $\alpha$ (pGEM-T), and selected with either kanamycin or ampicillin (Sigma). Doublestranded sequencing was performed using the dideoxy chain termination method with Sequenase Version 2.0 (United States Biochemical, Cleveland, $\mathrm{OH})$. The sequence of both strands was obtained using $M_{13}$ forward and reverse primers. Direct sequencing of the PCR product was performed as follows. Amplified product was concentrated using Centricon 30 concentrators (Amicon, Inc., Beverly, MA), $4 \mu \mathrm{l}$ of sample was used as template in an asymmetric PCR with a primer ratio of 1.0 pmol of limiting primer: 50 pmol of excess primer, $5 \mathrm{U}$ of Taq polymerase (Promega), and $1 \mu \mathrm{M}$ of dNTP. Asymmetric product was purified from excess primer and dNTPs by PCR spin-column chromatography (Qiagen), and dideoxy sequencing was performed using $8 \mu$ l of purified product with 10 pmol of primer (the opposite primer used in the asymmetric reaction).

Expression levels of RNA and Northern analysis. The mRNA expression levels were determined by slot-blot hybridization analysis, ${ }^{30}$ and RNA transcription analysis was determined by formaldehyde gel electrophoresis. ${ }^{28}$

\section{RESULTS}

Selection for increased chloroquine resistance in W2mef. Previously, we isolated a series of mefloquine-resistant lines from the multidrug-resistant line W2mef (Figure 1). ${ }^{6}$ Since

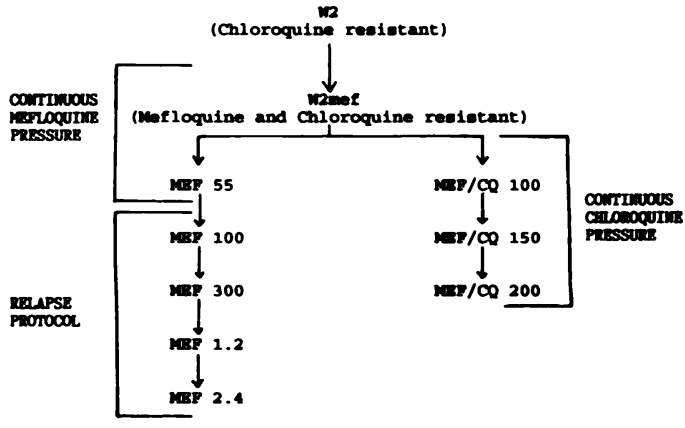

Figure 1. Selection protocols for the derivation of Plasmodium falciparum lines resistant to mefloquine hydrochloride (MEF) and chloroquine diphosphate (CQ) $(\mathrm{ng} / \mathrm{ml})$. Parasites were selected for increasing resistance to MEF and CQ as described previously and in the text. Parasite lines shown were stabilated and used in the current study.

selection for increased mefloquine resistance also resulted in lines exhibiting increased sensitivity to chloroquine, ${ }^{6}$ we reasoned that selection for increased chloroquine resistance in W2mef may result in the isolation of revertant lines, providing a model to study the molecular basis of drug resistance. The selection protocol initiated with chloroquine is shown in Figure 1. Continuous drug pressure was initiated with 100 $\mathrm{ng} / \mathrm{ml}$ of chloroquine, and concentrations were then increased in $50 \mathrm{ng} / \mathrm{ml}$ increments until lines that were resistant to $100 \mathrm{ng} / \mathrm{ml}$ (W2mefCQ100), $150 \mathrm{ng} / \mathrm{ml}$ (W2mefCQ150), and $200 \mathrm{ng} / \mathrm{ml}$ (W2mefCQ200) of chloroquine were derived over a 12-month period.

Microdilution assays based on ${ }^{3} \mathrm{H}$-hypoxanthine incorporation into parasite DNA were used to determine the drug susceptibility of W2mefCQ200 to chloroquine, mefloquine, halofantrine, quinine, and artemisinin (Table 1). As expected, the $\mathrm{IC}_{50}$ of chloroquine for W2mefCQ200 (102.34 $\pm 9.69 \mathrm{ng} / \mathrm{ml})$ was significantly increased above that of W2mef (62.61 $\pm 5.18 \mathrm{ng} / \mathrm{ml}$ ) (Table $1 ; P<0.01)$. Interestingly, W2mefCQ200 was now extremely susceptible to mefloquine with an $\mathrm{IC}_{50}$ of $2.06 \pm 1.18 \mathrm{ng} /$ $\mathrm{ml}$ as compared with $14.49 \pm 3.49 \mathrm{ng} / \mathrm{ml}$ for W2mef (Table 1; $P<0.001$ ), and was significantly more sensitive to mefloquine than $\mathrm{W} 2$, the progenitor clone of $\mathrm{W} 2 \mathrm{mef}$ at the $\mathrm{IC}_{90}(3.08$ $\pm 0.16 \mathrm{ng} / \mathrm{ml}$ versus $11.61 \pm 0.67 \mathrm{ng} / \mathrm{ml} ; P<$ $0.001), \mathrm{IC}_{95}(4.34 \pm 0.49 \mathrm{ng} / \mathrm{ml}$ versus $15.74 \pm$ $1.46 \mathrm{ng} / \mathrm{ml} ; P<0.001)$, and $\mathrm{IC}_{99}(9.35 \pm 2.33$ 
TABLE 1

Drug susceptibility profiles

\begin{tabular}{|c|c|c|c|c|c|}
\hline \multirow[b]{2}{*}{ Clone/line } & \multicolumn{5}{|c|}{$I C_{s 0}{ }^{*}$} \\
\hline & Chloroquine & Mefloquine & Halofantrine & Quinine & Artemisinin \\
\hline W2 & $91.70 \pm 8.14$ & $4.35 \pm 0.89$ & $0.37 \pm 0.01$ & $83.50 \pm 5.43$ & $1.97 \pm 0.46$ \\
\hline W2mef & $62.61 \pm 5.18$ & $14.49 \pm 3.49$ & $1.48 \pm 0.19$ & $56.32 \pm 4.17$ & $3.46 \pm 0.38$ \\
\hline Mef 2.4 & $48.35 \pm 4.57$ & $20.17 \pm 7.21$ & $3.42 \pm 1.86$ & $97.54 \pm 9.49$ & $3.59 \pm 0.45$ \\
\hline W2mefCQ200 & $102.34 \pm 9.69$ & $2.06 \pm 1.18$ & $0.18 \pm 0.05$ & $48.88 \pm 8.24$ & $3.20 \pm 0.40$ \\
\hline Sensitive $†$ & $<10.0$ & $<8.0$ & $<\mathrm{NE} \ddagger$ & $<25.0$ & $\mathbf{N E} \ddagger$ \\
\hline
\end{tabular}

* Fifty percent inhibitory concentration $\left(\mathrm{IC}_{\mathrm{s}_{0}}\right)$ determinations $(\mathrm{ng} / \mathrm{ml})$ for chloroquine disphosphate, quinine sulfate, mefloquine hydrochloride. halofantrine hydrochloride, and artemisinin with Plasmodium falciparum W2, W2mef, Mef 2.4, and W2mefCQ200. Values are means \pm SD of at least five separate determinations (two separate dilutions per determination).

$\dagger$ Drug reference levels for sensitive parasites are correlates of clinical and in vitro data established by the Walter Reed Army Institute of Research $\dagger$ Drug reference
and in reference 34.

$\ddagger \mathrm{NE}=$ not yet established.

$\mathrm{ng} / \mathrm{ml}$ versus $33.76 \pm 5.22 \mathrm{ng} / \mathrm{ml} ; P<0.001)$ levels. The $\mathrm{IC}_{50}$ of halofantrine was also significantly reduced, $0.18 \pm 0.05 \mathrm{ng} / \mathrm{ml}$ for W2mefCQ200 as compared with $1.48 \pm 0.19$ $\mathrm{ng} / \mathrm{ml}$ for W2mef $(P<0.001)$, indicating increased sensitivity to this antimalarial as well (Table 1). The $\mathrm{IC}_{50}$ values for $\mathrm{W} 2 \mathrm{mefCQ} 200$ to quinine indicated a slight decrease $(P<0.05$ versus $\mathrm{W} 2 \mathrm{mef})$, while repeated assays $(n=5)$ with Mef 2.4 indicated a slight increase in the $\mathrm{IC}_{50}$ as compared with $\mathrm{W} 2$ and W2mef $(P<$ 0.01; Table 1). The $\mathrm{IC}_{50}$ to artemisinin for W2mefCQ200 had not significantly changed from that of $W 2$ mef.

Amplification of pfmdrl in highly mefloquine-resistant lines. To determine $p f m d r l$ gene copy number, Southern blot hybridization analysis was performed on W2 and W2mef, the mefloquine passage lines Mef 55, Mef 100, Mef 300 , Mef 2.4, and the mefloquine-halofantrine revertant line W2mefCQ200. A 390-basepair (bp) pfindrl DNA fragment was used to probe Southern blots of a $\mathrm{Bgl}$ II digest of genomic DNA. In vitro selection for increasing mefloquine resistance resulted in a corresponding amplification of the pfmdrl gene in the mefloquine passage lines (Figures $2 \mathrm{~A}$ and $\mathrm{B}$ ) in comparison with the known single copy $C S P$ gene (Figures 2C and D). Dihydrofolate reductase was also found to be single copy in W2, Mef 300 , and Mef 2.4. The gene copy number of each of these lines (Table 2) was obtained following Southern blot analysis by direct scanning of the nitrocellulose membranes using a radioanalytical quantification imaging system since the linear capacity of radiographic film is rapidly exceeded, making densitometric determinations of copy number difficult. The reported values are ex- pressed as the ratio of $p f m d r l$ to $C S P$ and reflect at least two separate experiments. In agreement with previous findings, pfmdrl was amplified three-fold in the W2-mef clone. ${ }^{15}$ The Mef 55 line, selected with continuous pressure protocols to $55 \mathrm{ng} / \mathrm{ml}$, also demonstrated a three-fold amplification of the pfmdrl allele. Interestingly, an eight-fold amplification of pfmdrl was noted in the Mef 100, Mef 300, and Mef 2.4 lines, which were selected by discontinuous drug pressure with 100,300 , and $2,400 \mathrm{ng} / \mathrm{ml}$ of mefloquine, respectively (Figures 1 and 2 and Table 2). ${ }^{6}$ The mefloquine-halofantrine-sensitive revertant line W2mefCQ200 contained a single copy of pfmdrl, losing the three-fold amplification of pfmdrl that had been acquired during the induction of mefloquine resistance in W2mef. As expected, a single copy of the pfmdrl gene was noted in the chloroquine-resistant, mefloquinesensitive parasites W2 and FCR3 (Figure 2 and Table 2).

Expression of mRNA and Northern analysis. Previous studies have demonstrated enhanced pfmdrl transcript prevalence in mefloquine-resistant clones and isolates. ${ }^{15,17.31}$ Slot-blot hybridization analysis was used to determine mRNA expression levels of pfmdrl in W2, W2mef, Mef 2.4, and W2mefCQ200 (Figure 3). Direct scanning of nitrocellulose membranes indicated that equivalent amounts of total RNA were analyzed as indicated by hybridization with the $G B P$ gene control. An approximate three-fold increased pfmdrl mRNA expression was detected in W2Mef, and an eight-fold enhanced expression was detected in Mef 2.4 as compared with lowlevel expression in the mefloquine-sensitive clone W2 and the mefloquine-halofantrine revertant line W2mefCQ200 (Figure 3 and Table 2). North- 

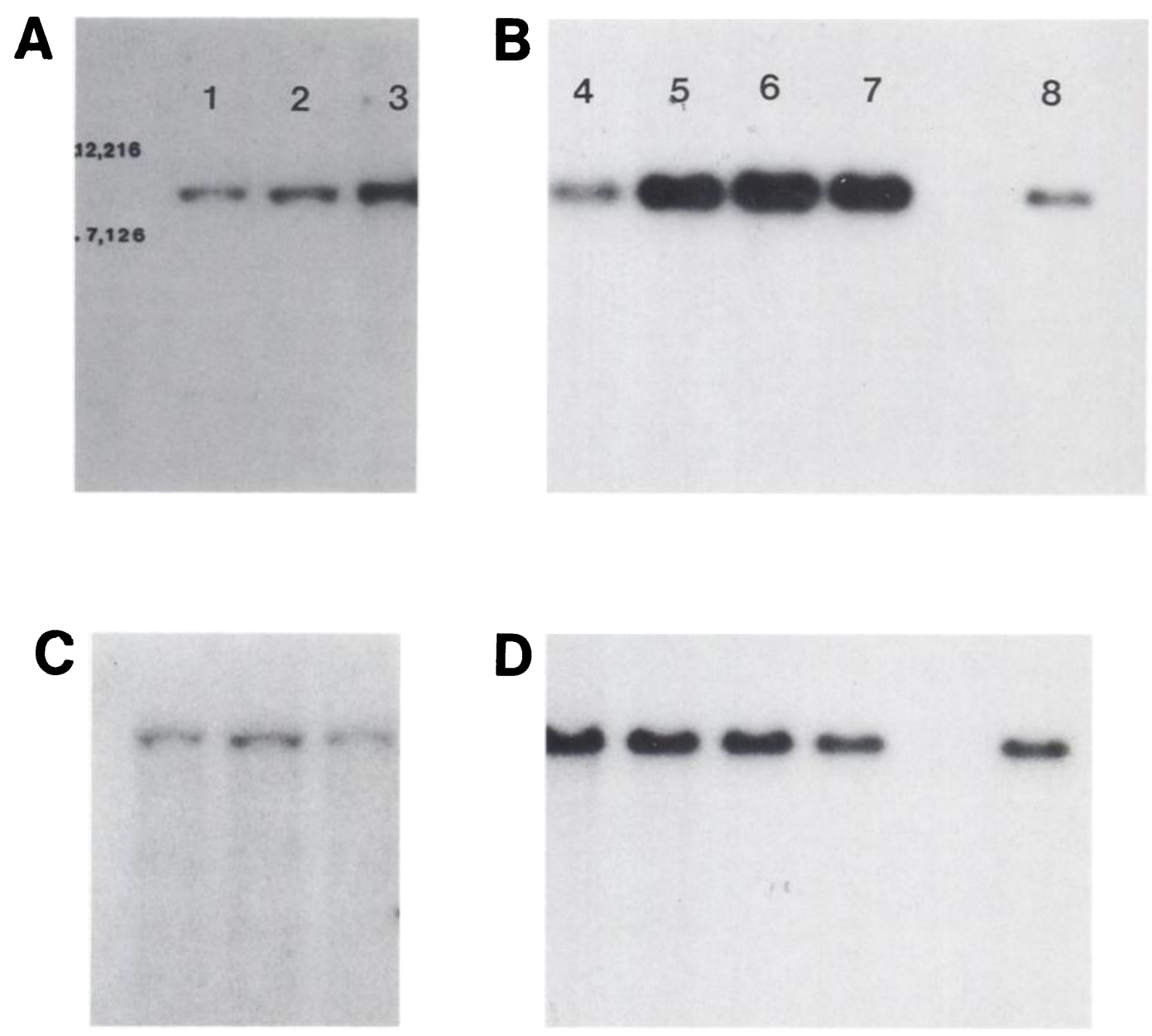

FIGURE 2. Southern blot analysis of the P-glycoprotein gene homolog ( $p f m d r l)$ in the Plasmodium falciparum passage lines. Four micrograms of genomic DNA of FCR3 (lane 1), W2 (lane 2), W2mef (lane 3), Mef 55 (lane 4), Mef 100 (lane 5), Mef 300 (lane 6), Mef 2.4 (lane 7), and W2mefCQ200 (lane 8) was digested with Bgl II, separated by electrophoresis on $0.7 \%$ agarose gels, transferred to nitrocellulose, and hybridized with either a ${ }^{32} \mathrm{P}$-labeled $\mathrm{pfmdrl}$ (A, 24-hr exposure; B, 36-hr exposure) or a circumsporozoite gene (C, 24-hr exposure; D, 36-hr exposure) DNA probe as described in the experimental procedures. Values on the left side of $\mathbf{A}$ are in basepairs.

ern analysis of agarose formaldehyde gels of latestage trophozoites of W2, W2mef, and Mef 2.4 also demonstrated the two major transcripts of the expected size that were significantly increased in amount in W2-mef and Mef 2.4 as compared with W2 (Figure 4).

Sequence analysis of pfmdrl. One to four amino acid changes have been correlated with the chloroquine resistance phenotype. The putative mutation reported for W2 and W2mef in pfmdrl, referred to as the $\mathrm{K} 1$ allele, was an $\mathrm{A}$ to $T$ point mutation at nucleotide position 754 , resulting in an asparagine (AAT) to tyrosine (TAT) change at amino acid 86. ${ }^{18}$ Since a tyrosine (TAT) to phenylalanine (TTT) change at position 184 has also been reported, ${ }^{17}$ oligonucleotide primers were constructed to amplify a 502 or 631-bp fragment spanning the point mutations at either nucleotides 754 or 1049, respectively. Extensive sequence analysis was performed on the PCR product and genomic subclones from W2, W2mef, Mef2.4, and W2mefCQ200. Direct sequencing of the asymmetric PCR product revealed the expected TAT at position 86 in W2 
TABLE 2

Gene copy number, mRNA expression levels, and sequence comparisons in the P-glycoprotein gene homolog (pfmdr1) gene among Plasmodium falciparum clones and lines

\begin{tabular}{|c|c|c|c|c|c|}
\hline \multirow[b]{2}{*}{ Parasite line } & \multirow{2}{*}{$\begin{array}{l}\text { Gene } \\
\text { copy/ } \\
\text { mRNA } \\
\text { levels }\end{array}$} & \multicolumn{2}{|c|}{$\begin{array}{l}\text { Nucleotide } \\
\text { at position }\end{array}$} & \multicolumn{2}{|c|}{$\begin{array}{l}\text { Amino acid } \\
\text { at position }\end{array}$} \\
\hline & & $755+$ & $1049+$ & $86+$ & $184 \dagger$ \\
\hline W2 & $1 / 1$ & TAT & TAT & Tyr & Tyr \\
\hline W2mef & $3 / 3$ & $\begin{array}{l}\text { TAT } \\
\text { TTT }\end{array}$ & TAT & $\begin{array}{l}\text { Tyr } \\
\text { Phe }\end{array}$ & Tyr \\
\hline $\begin{array}{l}\text { Mef } 55 \\
\text { Mef } 100 \\
\text { Mef } 300\end{array}$ & $\begin{array}{l}\text { 3/ND } \\
\text { 8/ND } \\
\text { 8/ND }\end{array}$ & $\begin{array}{l}\text { ND } \\
\text { ND } \\
\text { ND }\end{array}$ & $\begin{array}{l}\text { ND } \\
\text { ND } \\
\text { ND }\end{array}$ & $\begin{array}{l}\text { ND } \\
\text { ND } \\
\text { ND }\end{array}$ & $\begin{array}{l}\text { ND } \\
\text { ND } \\
\text { ND }\end{array}$ \\
\hline Mef 2.4 & $8 / 8$ & TTT & TAT & Phe & Tyr \\
\hline W2mefCQ200 & $1 / 1$ & TAT & TAT & Tyr & Tyr \\
\hline
\end{tabular}

* All values are rounded to the nearest integer. Gene copy number is expressed as a ratio of |pfmdrl/circumsporozoite protein| and mRNA levexpressed as a ratio of $\mid p f m d r 1 /$ circumsporozoite protein
els as a ratio of $|\mathrm{pfmdr}| / \mathrm{glycophorin}$ binding protein|.

+ Chloroquine-sensitive lines encode AAT (Asn) at nucleotide 755, and TAT (Tyr) at nucleotide 1049.'s

(Figure 5A); however, an additional $\mathrm{A}$ to $\mathrm{T}$ mutation at nucleotide 755 (TTT) was also noted in W2mef and Mef 2.4 (Figures 5B and C). Close inspection of the results revealed a faint band in the A lane of W2mef (see arrow, Figure 5B), which indicated a mixed sequence population at this locus. Since quantitative PCR was not used to obtain gene fragments for DNA sequencing, and since both W2mef and Mef 2.4 contained

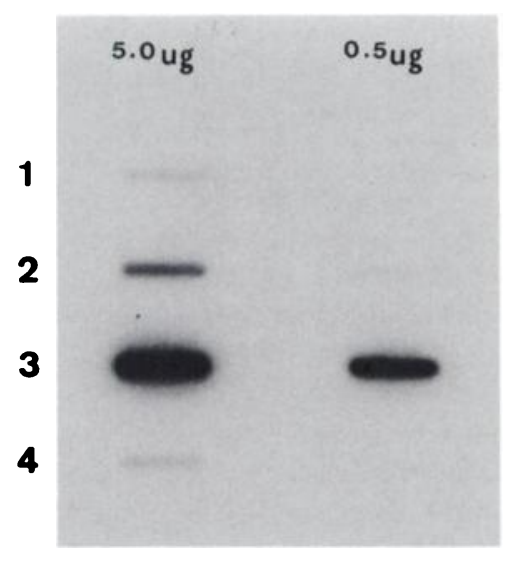

Figure 3. Slot-blot analysis of the P-glycoprotein gene homolog (pfmdrl) in Plasmodium falciparum lines W2 (lane 1), W2mef (lane 2), Mef 2.4 (lane 3), and W2mefCQ200 (lane 4). Total cellular RNA was isolated by the guanidinium isothiocyanate method, and 5 and $0.5 \mu \mathrm{g}$ of total RNA was applied to $\mathrm{Im}$ mobilon N (Millipore Corp., Bedford, MA) and hybridized to a pfmdrl or a glycophorin binding protein gene probe.

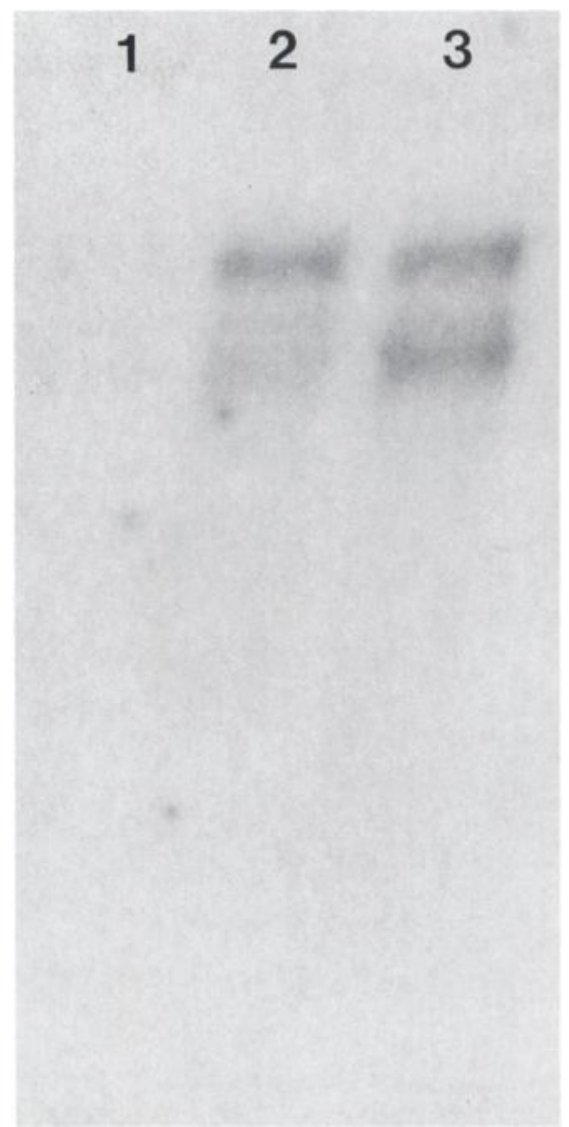

Figure 4. Northern analysis of the P-glycoprotein gene homolog (pfmdrl) in Plasmodium falciparum lines W2 (lane 1), W2mef (lane 2), and Mef 2.4 (lane 3 ). Five micrograms of total cellular RNA from trophozoite stage parasites was applied to Immobilon $\mathbf{N}$ (Millipore Corp., Bedford, MA) and hybridized to a pfmdrl gene probe.

multiple copies of pfmdrl, sequence analysis was performed on plasmid subclones of the PCR product isolated from these lines. The putative chloroquine-associated allele, TAT, was noted in 10 of 10 subclones of W2; however, analysis of this region in W2mef demonstrated only four of 16 subclones with the expected TAT sequence (Figure 5E), while the remainder had mutated to TTT (Figure 5D), resulting in an amino acid change from tyrosine (TAT) to phenylalanine (TTT). This mixed locus in W2mef was confirmed in clones that had been maintained in frozen storage since 1984, while sequence analysis of 24 plasmid subclones of Mef 2.4 demonstrated only TTT at this position. If the pfmdrl gene, 
A

\section{G $\quad \mathbf{A} \quad \mathbf{T} \mathbf{C}$}

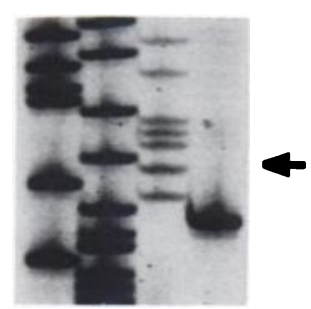

D

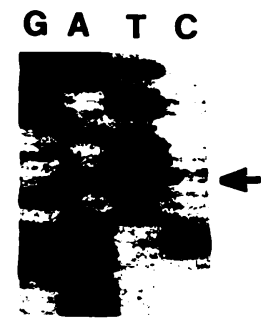

B

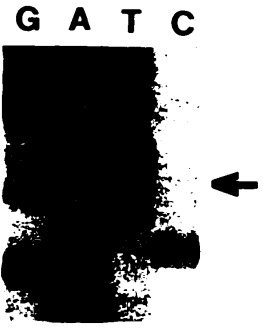

E

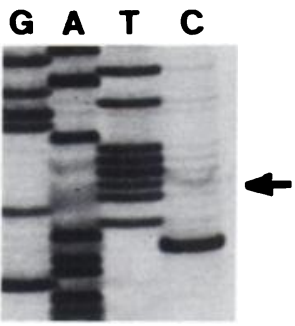

C

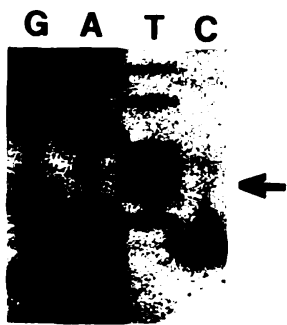

$\mathbf{F}$

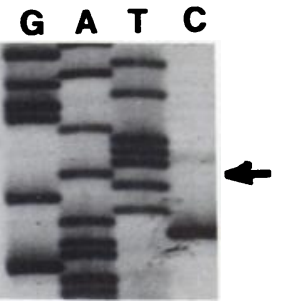

Figure 5. Variant allele in the P-glycoprotein gene homolog (pfmdrl) gene in the Plasmodium falciparum lines. Genomic DNA was amplified across a 502-basepair region encompassing the putative chloroquine (CQ)specific allele at nucleotide position 754. Direct sequencing of the polymerase chain reaction product of $A, W 2$; B, W2mef; and C, Mef 2.4, and double-stranded sequencing of representative independent plasmid clones of D and E, W2mef; and F, W2mefCQ200 demonstrate the variability at position 754/5. The arrows indicate the variant allele TAT or TTT. The gels are read from the bottom, G (lane 1), A (lane 2), T (lane 3), and C (lane 4).

and in particular this region of the gene, is under strong selective pressure and confers resistance to mefloquine, W2mefCQ200, which was sensitive to mefloquine and halofantrine, should reflect sequence changes at this allele. A 502-bp fragment encompassing this region was amplified by PCR, subcloned, and eight of eight plasmid subclones were sequenced and found to contain the putative chloroquine mutation (TAT) at position 86 (Figure 5).

Sequence analysis of the 631-bp PCR product and eight of eight genomic subclones of $\mathrm{W} 2$, W2mef, Mef 2.4, and W2mefCQ200 across nucleotide 1049 revealed tyrosine (TAT) at this position (Table 2). Thus changes at this position could not be correlated with mefloquine or halofantrine resistance in our lines.

\section{DISCUSSION}

Selection for enhanced mefloquine resistance from W2 to W2mef to Mef 2.4 resulted in lines demonstrating increased halofantrine resistance and increased chloroquine sensitivity. The slight increase in quinine resistance noted for these lines, and its decrease (albeit slight) following selection for chloroquine resistance, suggests that selection for high levels of resistance to mefloquine may also modulate levels of quinine resistance. Interestingly, increased mefloquine and quinine resistance were noted following selection for halofantrine resistance in vitro in both chloroquine-sensitive and -resistant parasites. ${ }^{32}$ Current observations with clinical isolates from Africa and Thailand also indicate that responses 
to mefloquine and halofantrine demonstrate a positive correlation with each other and an inverse correlation with chloroquine resistance. ${ }^{33-}$ 36 Whether or not quinine susceptibility varies in any consistent way with responses to mefloquine and halofantrine is less clear; however, in vivo studies suggest that quinine demonstrates a positive correlation with these drugs, and an inverse correlation with chloroquine resistance..$^{33,34} \mathrm{Se}$ lection for increased chloroquine resistance in W2mef resulted in a line demonstrating a revertant sensitive phenotype to mefloquine and halofantrine. These results are consistent with those reporting a two-fold decrease in the $\mathrm{IC}_{50}$ of mefloquine following selection for increased chloroquine resistance in $\mathrm{W} 2 \mathrm{mef},{ }^{21}$ although the absolute values of $\mathrm{IC}_{50}$ cannot be compared because of the different assay methodology. Susceptibility to halofantrine for these lines was not reported. The apparent lack of modulation of artemisinin resistance by quinoline-containing methanols suggests that $p$ fmdrl may not mediate a truly classic MDR phenotype in $P$. falciparum.

Increased resistance to mefloquine and halofantrine correlated with amplification and overexpression of pfmdrl; however, lines selected with mefloquine concentrations of $100 \mathrm{ng} / \mathrm{ml}$ or greater did not demonstrate proportionately higher levels of pfmdrl amplification and overexpression. Analysis of the $\mathrm{W} 2 \mathrm{mefCQ} 200$ line revealed that the three-fold amplification of pfmdrl noted in the progenitor line, W2mef, had been lost. The W2mefCQ200 line now contained a single copy of the gene that was not overexpressed. These results are consistent with studies that indicate that amplification of pfmdrl does not correlate with increased chloroquine resistance, ${ }^{17.21 .37}$ as well as with studies suggesting that pfmdrl amplification correlates with increased mefloquine and halofantrine resistance. ${ }^{17}$

Examination of the intragenic allele at amino acid 86, previously associated with chloroquine resistance, ${ }^{18}$ suggested that a specific hydrophobic domain mutation was derived depending upon the antimalarial used in the selection protocol. The identification in W2mef of a mixed sequence population with TAT at position 754 , and a previously unidentified mutation TTT at position 755 , emphasizes a potential problem associated with the current technique of consensus sequencing of the PCR product since all sequence changes may not be identified. This un- derscores the importance of sequencing individual clones from genes that are amplified.

That stepwise selection with mefloquine results in the specific amplification of pfmdrl with only the mefloquine-associated mutation (86Phe) in Mef 2.4 is significant and not without precedent. Cross-resistance in human KB carcinoma cells was found to result from a cluster of point mutations in the MDR1 gene that resulted in a Gly-185 to Val-185 substitution in the Pglycoprotein. ${ }^{38}$ The mutations were identified in a cell line where the wild-type MDR1 was amplified, yet selection for the next level of resistance resulted in all amplified copies of the gene carrying the same mutations. ${ }^{39}$ While the $\mathrm{IC}_{50}$ of chloroquine has decreased in Mef 2.4, the parasite remains resistant to chloroquine, suggesting that either 86-Tyr is not critical for resistance, or that the 86-Phe change remains a competent allele for chloroquine resistance.

The loss of amplified genes carrying the mefloquine-halofantrine-associated mutation, 86Phe (TTT), subsequent reversion to a mefloquine-halofantrine-sensitive phenotype, and selection for an allele (TAT) associated with chloroquine resistance in $\mathrm{W} 2$ mefCQ200 suggest that this area of the gene is under heavy selective pressure from quinoline-containing compounds. While appearing to support a role for the $\mathrm{Kl}$ allele in chloroquine resistance, ${ }^{18}$ these results seem to contradict those that suggested that there was no link between pfmdrl and chloroquine resistance, but implicated an allele on chromosome $7 .^{20}$ In support of these findings, chloroquine-resistant isolates from Thailand did not demonstrate the putative chloroquine resistance-associated $\mathrm{K} 1$ allele (TAT). ${ }^{17}$ In both studies, however, the clones and isolates used contained multiple copies of the pfmdrl gene. For example, although it is clear that chloroquine resistance maps to a locus on chromosome 7,20 the resistant clone D2d, derived from W2mef, likely contained two alleles, one previously associated with chloroquine resistance (86-Tyr), ${ }^{18}$ and the newly identified mutation (86-Phe) associated with mefloquine and halofantrine resistance. Since the genotype of all pfindrl copies of the parents or progeny of the genetic cross has not been determined, pfmdrl cannot be excluded as a genetic determinant modulating mefloquine and/or chloroquine resistance.

Although the 86-Tyr to 86-Phe mutation located between transmembrane (TM) domains 1 
and 2 in pfmdrl in our passage lines is the strongest link, to date, of a membrane-associated mutation with mefloquine and halofantrine resistance, the high gene copy number of Mef 2.4 has made mutational analysis difficult. Clearly, additional mutations in pfmdrl or yet unrecognized genes may also function in resistance. Studies using clinical isolates from Thailand indicated that mefloquine resistance may be associated with an $\mathrm{A}$ to $\mathrm{T}$ mutation at nucleotide 1049 resulting in a Tyr to Phe change between TM2 and 3. ${ }^{17}$ That this mutation was also noted in the lone mefloquine/halofantrine sensitive line (TM335) suggests that this mutation does not necessarily correlate with resistance to these drugs. While our data support this interpretation, it should be noted that mutations within TM domains of other ABC gene family members, such as TM11 of rodent $m d r l$ and $m d r 3$ and TM1, TM6, and TM10 of the human cystic fibrosis transmembrane conductance regulator protein (CFTR), have also been correlated with specificity to various compounds. ${ }^{40.41}$ Although analysis of chimeric $M D R 1 / M D R 2$ genes has indicated that neither point mutations nor specific amino acid sequences encoded drug-resistance profiles, drug binding and recognition seemed to involve higher-order structure affected by multiple, independent parts of the molecule. ${ }^{42}$ Recent studies have indicated that the first cytoplasmic loop of MDR 1, and in particular residues 165, 166, 168 , and 169 , appear to confer functional multidrug transporter activity. ${ }^{43}$ If drug recognition and binding involves the participation of membrane domains from both halves of the pfmdrl protein product, P-glycoprotein homolog 1 (Pgh1), in $P$. falciparum, mutations in or near one or more transmembrane domains may be critical determinants of resistance to mefloquine and halofantrine.

Although the results presented provide strong support for $\mathrm{pfmdrl}$ mediating cross-resistance to mefloquine, halofantrine, and perhaps quinine in $P$. falciparum, it is also not yet clear how Pghl could modulate resistance to these drugs. In MDR cells, the most important determinant of transport by the putative export pump is a compound's relative hydrophobicity. ${ }^{3}$ Compounds concentrated in plasma membranes are thought to be detected and expelled as they partition into the membrane in a manner similar to a hydrophobic vacuum cleaner, ${ }^{44}$ as well as through the channel of the transporter. ${ }^{43}$ In contrast, Pghl has been localized principally to the surface of the digestive vacuole of the parasite,$^{37}$ the proposed site of action of these drugs. ${ }^{45,46}$ Although the protein may be positioned to directly affect drug levels within this vacuole, its actual orientation (export versus import) within the vacuole membrane is not known. If pfmdrl functions in a manner similar to P-glycoprotein in MDR cells, mefloquine and halofantrine, which are more tightly associated with membranes than chloroquine or quinine, may be better substrates for transport. With only minor amounts of Pgh1 localized to the plasma membrane of the parasite, ${ }^{37}$ however, the mechanism by which these drugs could then move from the digestive vacuole, through the parasite plasma membrane, the parasitophorous vacuole membrane, and finally through the cytoplasm and plasma membrane of the erythrocyte, remains unknown.

Alternatively, studies with MDR tumor cells suggest that $\mathrm{P}$-glycoprotein may function as a proton/chloride pump. ${ }^{3}$ Since quinoline-containing antimalarials as weak bases are concentrated by the acidic digestive vacuole, ${ }^{45,46}$ regulation of $\mathrm{pH}$ of this organelle has also been suggested as a possible function of Pgh $1 .{ }^{47}$ In support of these studies, Bray and others have suggested that changes in chloroquine accumulation (presumably due to increased vacuole $\mathrm{pH}$ ), and not efflux from the food vacuole, may determine resistance. $^{48}$

Analysis of our progressively more drug-resistant parasite lines indicated that a single mutation in Pghl could not alone be responsible for high levels of resistance since the Mef 100, Mef 300, and Mef 2.4 lines contained equivalently amplified and overexpressed pfmdrl genes, and yet Mef 2.4 is significantly more resistant. ${ }^{6}$ In addition, selection for the revertant line with chloroquine resulted in hypersensitivity to mefloquine and halofantrine and decreased quinine resistance as compared with the progenitor clone W2. Since this revertant line retained the putative chloroquine-associated allele (TAT) found in pfmdrl of $\mathrm{W} 2$, yet was more sensitive than W2 to these compounds, additional genetic changes must have occurred. The availability of an in vitro model with lines demonstrating increased resistance, as well as revertant lines, should allow us not only to begin to dissect the complex mechanisms of drug resistance in $P$. falciparum, but also to examine the biological 
function of Pghl in the parasite and its potential role in mediating resistance to antimalarials.

Acknowledgments: We thank Dr. Lorraine K. Alexander for help with the statistical analyses. We are grateful to the North Carolina branch of the American Red Cross for the provision of blood and plasma.

Financial support: This work was supported by research grants from the John Reed Trust to Sheila A. Peel, and the North Carolina Biotechnology Center (9213-ARG-0405) to Ralph S. Baric and Jean Handy. Ralph S. Baric is a recipient of an established investigator award from the American Heart Association (AHA-89-0193).

Authors' addresses: Sheila A. Peel, Patricia Bright, Boyd Yount, and Ralph S. Baric, Department of Epidemiology, CB 7400, McGavran-Greenberg Hall, University of North Carolina at Chapel Hill, Chapel Hill, NC, 27599-7400. Jean Handy, CB 7600, Clinical Microbiology and Immunology Laboratories, UNC Hospitals, Chapel Hill, NC 27599-7600.

\section{REFERENCES}

1. Peters $W, 1985$. The problem of drug resistance in malaria. Parasitology 90: 705-715.

2. Oakes SC, Mitchel VS, Pearson GW, Carpenter CCJ, 1991. Malaria. Obstacles and opportunities. A Report of the Committee for the Study on Malaria Prevention and Control: Status Revieu and Alternative Strategies. Washington, DC: Division of International Health, Institute of Medicine, National Academy Press, 144-166.

3. Gottesman MM, Pastan I, 1993. Biochemistry of multidrug resistance mediated by the multidrug transporter. Annu Rev Biochem 62: 385-427.

4. Endicott JA, Ling V 1989. The biochemistry of P-glycoprotein-mediated multidrug resistance. Annu Rev Biochem 58: 137-171.

5. Oduola AJ, Milhous WK, Weatherly NF, Bowdre JH, Desjardins RE, 1988. Plasmodium falciparum: induction of resistance to mefloquine in cloned strains by continuous drug exposure in vitro. Exp Parasitol 67: 354-360.

6. Peel SA, Merritt SC, Handy J, Baric RS, 1993. Derivation of highly mefloquine-resistant lines from Plasmodium falciparum in vitro. Am J Trop Med. Hyg 48: 385-397.

7. Krogstad DJ, Gluzman IY, Kyle DF, Oduola AMJ, Martin SK, Milhous WK, Schlesinger PH, 1987. Efflux of chloroquine from $P$. falciparum: mechanisms of chloroquine resistance. Science 238: 1283-1285.

8. Martin SK, Oduola AMJ, Milhous WK, 1987. Reversal of chloroquine resistance in Plasmodium falciparum by verapamil. Science 235: 899901.

9. Bitonti AJ, Sjoerdsma A, McCann PP, Kyle DE, Oduola AMJ, Rossan RN, Milhous K, Davidson DE, 1988. Reversal of chloroquine resistance in the malarial parasite Plasmodium falciparum by desipramine. Science 242: 1301-1303.
10. Peters W, Ekong R, Robinson BL, Warhurst DC, Pan XQ, 1989. Antihistaminic drugs that reverse chloroquine resistance in Plasmodium falciparum. Lancet ii: 334-335.

11. Kyle DE, Oduola AM J, Martin SK, Milhous WK, 1990. Plasmodium falciparum: modulation by calcium antagonists of resistance to chloroquine, desethylchloroquine, quinine, and quinidine in vitro. Trans $R$ Soc Trop Med Hyg 84: 474-478.

12. Oduola AMJ, Omitowoju GO, Gerena L, Kyle DE, Milhous WK, Sowunmi A, Salako LA 1993. Reversal of mefloquine resistance with penfluridol in isolates of Plasmodium falciparum from south-west Nigeria. Trans $R$ Soc Trop Med Hyg 87: 81-83.

13. Peters W, Robinson BL, 1991. The chemotherapy of rodent malaria. XLVI. Reversal of mefloquine resistance in rodent Plasmodium. Ann Trop Med Parasitol 85: 5-10.

14. Foote SJ, Thompson JK, Cowman AF, Kemp DJ, 1989. Amplification of the multidrug resistance gene in some chloroquine-resistant isolates of $\boldsymbol{P}$. falciparum. Cell 57: 921-930.

15. Wilson CM, Serrano AE, Wasley AM, Bogenschutz MP, Shankar AH, Wirth DF, 1989. Amplification of a gene related to mammalian $\mathrm{mdr}$ genes in drug resistant Plasmodium falciparum. Science 244: 1184-1186.

16. Hyde SC, 1990. Structural model of ATP-binding proteins associated with cystic fibrosis, multidrug resistance, and bacterial transport. Nature 346: 362-365.

17. Wilson CM, Volkerman SK, Thaithong S, Martin RK, Kyle DE, Milhous WK, Wirth DF, 1993. Amplification of pfmdrl associated with mefloquine and halofantrine resistance in Plasmodium falciparum from Thailand. Mol Biochem Parasitol 57: 151-160.

18. Foote SJ, Kyle DE, Martin RK, Oduola AMJ, Forsyth K, Kemp DJ, Cowman AF, 1990. Several alleles of the multidrug resistance gene are closely linked to chloroquine resistance in Plasmodium falciparum. Nature 345: 255-258.

19. Wellems TE, Panton LJ, Gluzman IY, do Rosario VE, Gwadz RW, Walker-Jonah A, Krogstad DJ, 1990. Chloroquine resistance not linked to $\mathrm{mdr}$ like genes in a Plasmodium falciparum cross. Nature 345: 253-255.

20. Wellems TE, Walker-Jonah A, Panton LJ, 1991. Genetic mapping of the chloroquine resistant locus on Plasmodium falciparum chromosome 7. Proc Natl Acad Sci USA 88: 3382-3386.

21. Barnes DA, Foote SJ, Galatis D, Kemp DJ, Cowman AF, 1992. Selection for high-level chloroquine resistance results in deamplification of the pfmdrl gene and increased sensitivity to mefloquine in Plasmodium falciparum. EMBO $\mathrm{J} 11$ : 3067-3075

22. Desjardins RE, Canfield CJ, Haynes JD, Chulay JD, 1979. Quantitative assessment of antimalarial activity in vitro by a semiautomated microdilution technique. Antimicrob Agents Chemother 16: 710-718.

23. Jobson KJH, Jennings MW, 1991. The structure 
of the calmodulin gene of Plasmodium falciparum. Mol Biochem Parasitol 46: 19-34.

24. Kunter S, Breuer WV, Ginsburg H, Aley SB, Cabantchik ZI, 1985. Characterization of permeation pathways in the plasma membrane of human erythrocytes infected with early stages of Plasmodium falciparum: association with parasite development. J Cell Physiol 125: 521-527.

25. Chomczynski P, Sacchi N, 1987. Single-step method of RNA isolation by acid guanidinium thiocyanate-phenol-chloroform extraction. Anal Biochem 162: 156-159.

26. Lockyer MJ, Schwartz RT, 1987. Strain variations in the circumsporozoite protein gene of Plas modium falciparum. Mol Biochem Parasitol 22. 101-108.

27. Kochan J, Perkins M, Ravetch JV, 1986. A tandemly repeated sequence determines the binding domain for an erythrocyte receptor binding protein of $P$. falciparum. Cell 44: 689-696.

28. Sambrook J, Fritsch EF, Maniatis T, 1989. Molecular Cloning: A Laboratory Manual. Second Edition. Cold Spring Harbor, NY: Cold Spring Harbor Press.

29. Southern EM, 1975. Detection of specific sequences among DNA fragments separated by gel electrophoresis. J Mol Biol 98: 503-517.

30. Kafatos FC, Jones WC, Efstratiadis A, 1979. Determination of nucleic acid sequence homologies and relative concentrations by dot blot hybridization procedure. Nucleic Acids Res 7: 1541-1552.

31. Volkerman SK, Wilson CM, Wirth DF, 1993. Stage specific transcripts of the Plasmodium falciparum pfmdrl gene. Mol Biochem Parasitol 57: 203-212.

32. Nateghpour M, Ward SA, Howells RE, 1993. Development of halofantrine resistance and determination of cross-resistance patterns in Plasmodium falciparum. Antimicrob Agents Chemother 37: 2337-2343.

33. Webster HK, Thaithong S, Pavanand K, Yongvanitchit K, Pinswasdi C, Boudreau EF, 1985. Cloning and characterization of mefloquine-resistant Plasmodium falciparum from Thailand. Am J Trop Med Hyg 34: 1022-1027.

34. Webster HK, Boudreau EF, Pavanand K, Yongvanitchit K, Pang LW, 1985. Antimalarial drug susceptibility testing of Plasmodium falciparum in Thailand using a microdilution radioisotope method. Am J Trop Med Hyg 34: 228-235.

35. Basco LK, Le Bras J, 1992. In vitro activity of halofantrine and its relationship to other standard antimalarial drugs against African isolates and clones of Plasmodium falciparum. Am J Trop Med Hyg 47: 521-527.

36. Childs GE, Boudreau EF, Wimonwattratee T, Pang L, Milhous WK, 1991. In vitro and clinical cor- relates of mefloquine resistance of Plasmodium falciparum in eastern Thailand. Am J Trop Med Hyg 44: 553-559.

37. Cowman AF, Karcz S, Galatis D, Culvenor JG, 1991. A P-glycoprotein homologue of Plasmodium falciparum is located on the digestive vacuole. J Cell Biol 113: 1033-1042.

38. Choi K, Chen C, Kriegler M, Roninson IB, 1988. An altered pattern of cross-resistance in multidrug resistant human cells results from spontaneous mutations in the mdrl (P-glycoprotein) gene. Cell 53: 519-529.

39. Roninson IB, 1992. The role of the MDR1 (Pglycoprotein) gene in multidrug resistance in vitro and in vivo. Biochem Pharmacol 43: 95102.

40. Gros P, Dhir R, Croop J, Talbot F, 1991. A single amino acid substitution strongly modulates the activity and substrate specificity of the mouse mdrl and mdr3 efflux pumps. Proc Natl Acad Sci USA 88: 7289-7293.

41. Anderson MP, Gregory RJ, Thompson S, Souza DW, Sucharita P, Mulligan RC, Smith AE, Welsh MJ, 1991. Demonstration that CFTR is a chloride channel by alternation of its anion specificity. Science 253: 202-205.

42. Dhir $R$, Gros $P, 1992$. Functional analysis of chimeric proteins constructed by exchanging homologous domains of two P-glycoprotein conferring distinct drug resistance profiles. Biochemtry 31: 6103-6110.

43. Currier SJ, Kane SE, Willingham MC, Cardarelli CO, Pastan I, Gottesman MM, 1992. Identification of residues in the first cytoplasmic loop of P-glycoprotein involved in the function of chimeric human MDR1-MDR2 transporters. $J$ Biol Chem 267: 25153-25159.

44. Raviv Y, Pollard HB, Bruggemann EP, Pastan I, Gottesman MM, 1990. Photosensitized labeling of a functional multidrug transporter in living drug resistant tumor cells. J Biol Chem 265: 3975-3980.

45. Yayon A, Cabantchik ZI, Ginsburg H, 1984. Identification of the acidic compartment of Plasmodium falciparum-infected human erythrocytes as the target of the antimalarial drug chloroquine. EMBO J 3: 2695-2700.

46. Krogstad DJ, Schlesinger PH, Gluzman IY, 1985. Antimalarials increase vesicle $\mathrm{pH}$ in Plasmodium falciparum. J Cell Biol 101: 2302-2309.

47. Ginsberg H, Krugliak M, 1992. Quinoline-containing antimalarials-mode of action, drug resistance and reversal. An update with unresolved puzzles. Biochem Pharmacol 43: 63-70.

48. Bray PG, Howells RE, Ritchie GY, Ward SA, 1992. Rapid chloroquine efflux phenotype in both chloroquine-sensitive and chloroquine-resistant Plasmodium falciparum. Biochem Pharmacol 44: 1317-1324. 